\section{Endosonography \\ Probe-Guided \\ Endoscopic Resection \\ of Small Flat Rectal \\ Carcinoid Tumor \\ Using Band Ligation \\ Technique}

K. Akahoshi ${ }^{1}$, T. Fujimaru ${ }^{1}$,

K. Nakanishi ${ }^{2}$, N. Harada ${ }^{3}$,

H. Nawata ${ }^{3}$

${ }^{1}$ Dept. of Gastroenterology,

Aso lizuka Hospital, lizuka, Japan

2 Dept. of Pathology, Aso lizuka Hospital, lizuka, Japan

${ }^{3}$ Third Dept. of Internal Medicine,

Faculty of Medicine, Kyushu University,

Fukuoka, Japan

Corresponding Author

K. Akahoshi, M.D., Ph.D.

Dept. of Gastroenterology

Aso lizuka Hospital

3-83 Yoshio

lizuka 820-8505

Japan

Fax: $\quad$ + 81-948-298747

Email: akahoshi-kh1@aso-group.co.jp

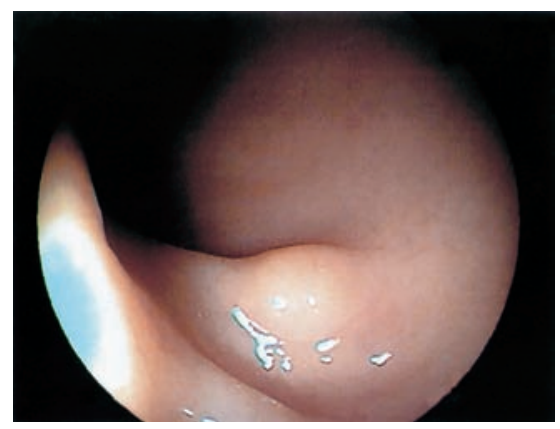

Figure 1 Colonoscopy on a 42year-old woman revealed a small rectal submucosal nodule.

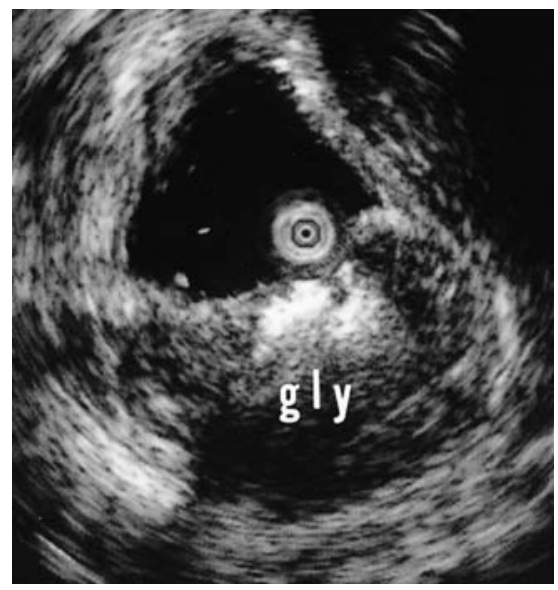

Figure 3 The tumor was treated by endosonography probe-guided endoscopic resection using band ligation, by means of a gastroduodenoscope with an attached singleband ligator (Sumitomo Bakelite; Tokyo, Japan), and $5 \mathrm{ml}$ of epinephrine-supplemented glycerin solution (gly) was injected underneath the lesion. Endosonography confirmed separation of the tumor from underlying muscle layer.

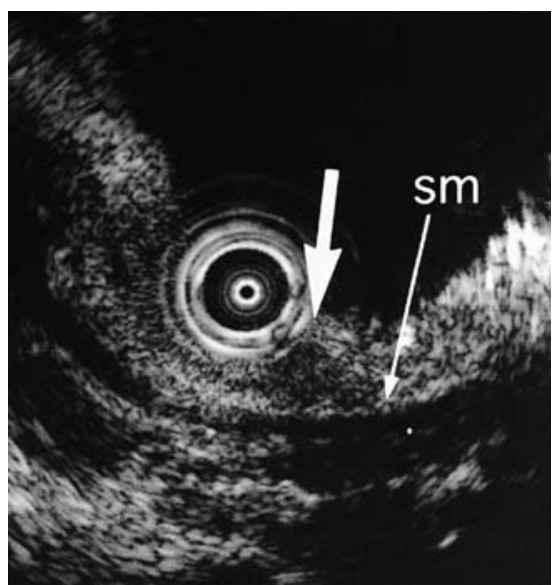

Figure 2 Subsequent endosonography using a $12-\mathrm{MHz}$ ultrasound miniprobe (SP-701; Fujinon, Omiya, Japan) demonstrated a hypoechoic solid tumor (arrow) in the superficial submucosa (sm).

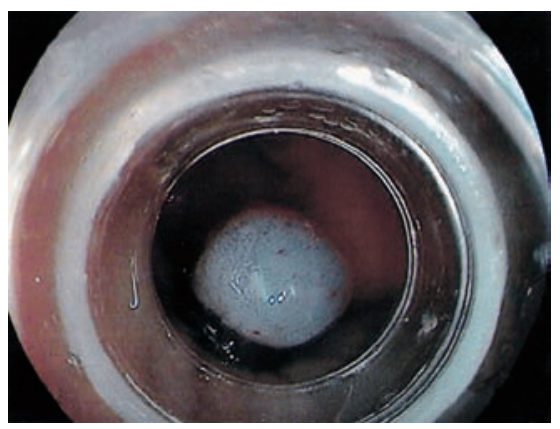

Figure 4 The lesion was aspirated into the ligator and the band was deployed, creating a bulging polyp. A snare polypectomy was performed below the band. Histological examination confirmed that the carcinoid tumor had been completely excised. 